\title{
Colpotomy in total laparoscopic hysterectomy without using an energy source: a new approach
}

\author{
Pandurang Ramchandra Rotithor ${ }^{1}$ \\ Keywords: colpotomy, energy source, laparoscopic hysterectomy
}

\begin{abstract}
Currently, energy sources are used in the form of either monopolar current or harmonic scalpel for colpotomy in total laparoscopic hysterectomy. This is associated with lateral thermal damage to adjacent organs such as the urinary bladder or lower ureter. The risk of scar dehiscence with this method is higher than that for abdominal hysterectomy. The objective of this new technique is to reduce these complications. The colpotomy is done using a blade and scissors through the vaginal tube without using any energy source. The resulting edge of the cut is sharper than that done by cautery, making it easy to pick full thickness of vagina. Colpotomy with this method is quicker than when using an energy source. There are also no toxic fumes thus visibility is not affected.

${ }^{1}$ IMAX Multispeciality Hospital, Wagholi, Pune, Maharashtra, India 412101
\end{abstract}

\section{Introduction}

Colpotomy in total laparoscopic hysterectomy is generally done using an energy source; the most common ones being monopolar energy or harmonic scalpel. Colpotomy in abdominal hysterectomy is usually done without using such sources and is associated with less chance of scar dehiscence. ${ }^{1}$ There is an increased incidence of lateral thermal damage to the urinary bladder and ureter if an excessive energy source is used in laparoscopic hysterectomy; sometimes this is not noted during surgery but becomes evident after a few days to 3 weeks. ${ }^{2}$ The incidence of vaginal scar dehiscence is found to be higher in total laparoscopic hysterectomy than either abdominal or vaginal hysterectomy. ${ }^{1}$

All coagulation devices have a distinct thermal spread which is dependent on the type of mode, the application time and the power setting. ${ }^{3}$ Hefermehl et al. found that monopolar mode causes thermal spread of $3.5 \mathrm{~mm}$ when applied for 1 second and after 2 seconds the spread was more than $20 \mathrm{~mm}$. For bipolar mode it was $2.2 \mathrm{~mm}$ for 1 second and $3.6 \mathrm{~mm}$ at 2 seconds, for

Please cite this paper as: Rotithor PR. Colpotomy in total laparoscopic hysterectomy without using an energy source: a new approach. Proceedings in Obstetrics and Gynecology, 2014;4(3):Article 8 [ 10 p.]. Available from: http://ir.uiowa.edu/pog/. Free full text article.

Corresponding author: Dr. Pandurang Ramchandra Rotithor. IMAX Multispeciality Hospital, Wagholi, Pune, Maharashtra, India 412101. E-Mail: pandurangrotithor@gmail.com.

Financial Disclosure: The author reports no conflict of interest.

Copyright: (c) 2014 Rotithor. This is an open-access article distributed under the terms of the Creative Commons Attribution License, which permits unrestricted use, distribution, and reproduction in any medium, provided the original author and source are credited. 
PK and LigaSure it was $3.9 \mathrm{~mm}$ and 2.8 $\mathrm{mm}$ respectively. For ultrasound the thermal spread was $2.9 \mathrm{~mm}$.

Gruber et al. studied energy induced damage in the vagina of swine during laparoscopic hysterectomy. ${ }^{4}$ They concluded that all energy sources cause damage due to lateral thermal spread with the least damage due to the harmonic scalpel and the maximum damage due to the bipolar mode. Sutton et al. studied various energy sources for lateral thermal damage in porcine muscle cuts and found that the degree of thermal damage varied with the instrument type, the power setting and the application time with monopolar diathermy resulting in the highest temperature and tissue damage. ${ }^{5}$

Rappaport et al. studied the effect of electrocautery on wound healing in midline laparotomy incisions in rats. They found that tensile strength was significantly reduced where coagulation current was used as compared with a scalpel and that there was more tissue necrosis, inflammation and adhesion formation in animals where an energy source was used. ${ }^{6}$

In the technique reported here, use of an energy source is avoided as far as possible. This may help to reduce the incidence of vaginal scar dehiscence.

\section{Technique description}

This technique is similar to total laparoscopic hysterectomy up to the point when the uterine arteries on both sides are coagulated and cut. After the uterine artery on both sides has been desiccated or tied, the blade handle is loaded with a \#11 blade (Figure 1).

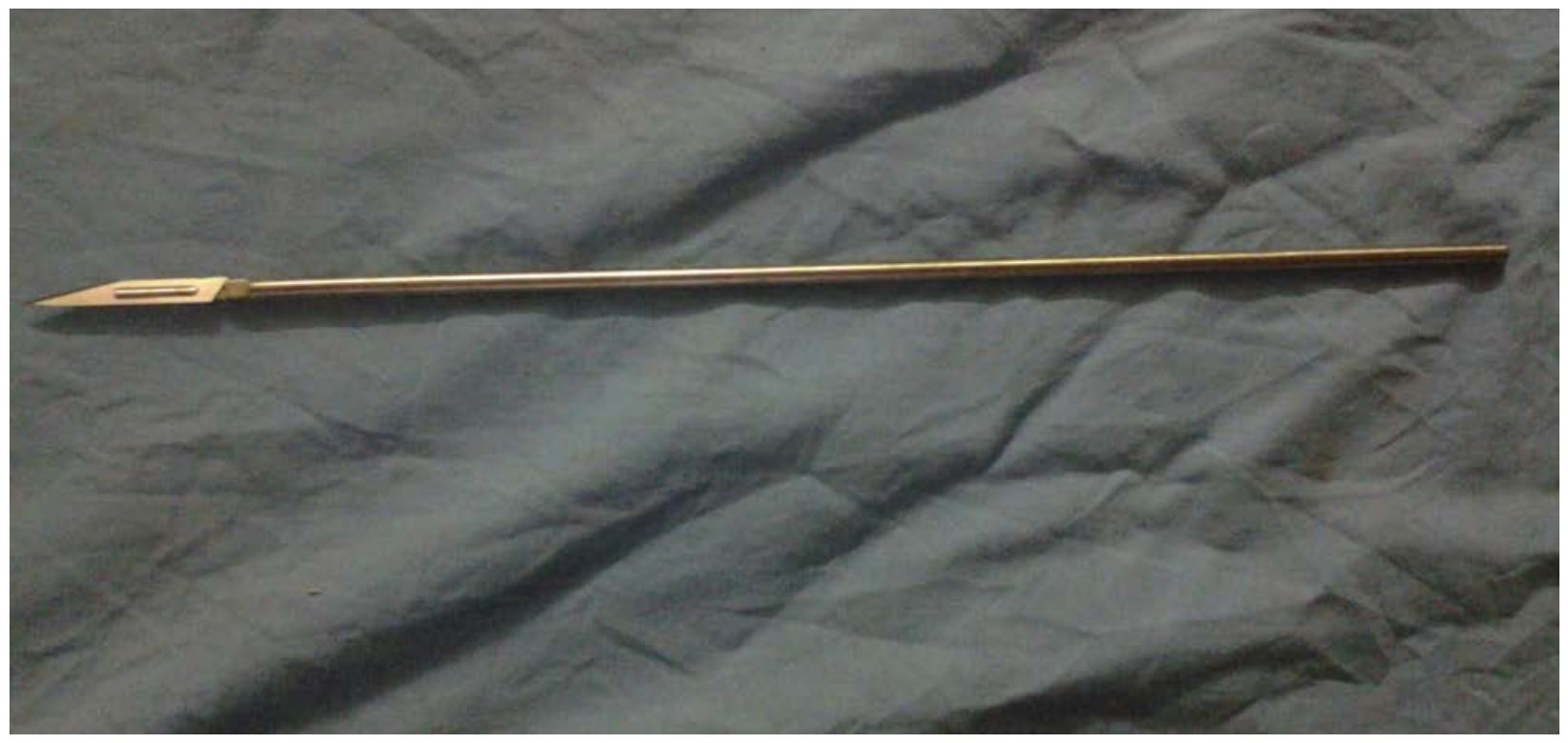

Figure 1. \#11 blade is mounted on the blade handle 
The vaginal tube is loaded with a blade handle fitted with a \# 11 blade (Figure 2). Sterile gel is applied to the tube for easy introduction. The blade handle is pulled back and the tube is introduced in the vagina. The tube is pushed in the vagina to stretch it. The vaginal tube acts as a colpotomizer. The stretching of the vagina demarcates the rim of the tube from the laparoscopic view, which helps to highlight the line along with which the vagina is to be cut.

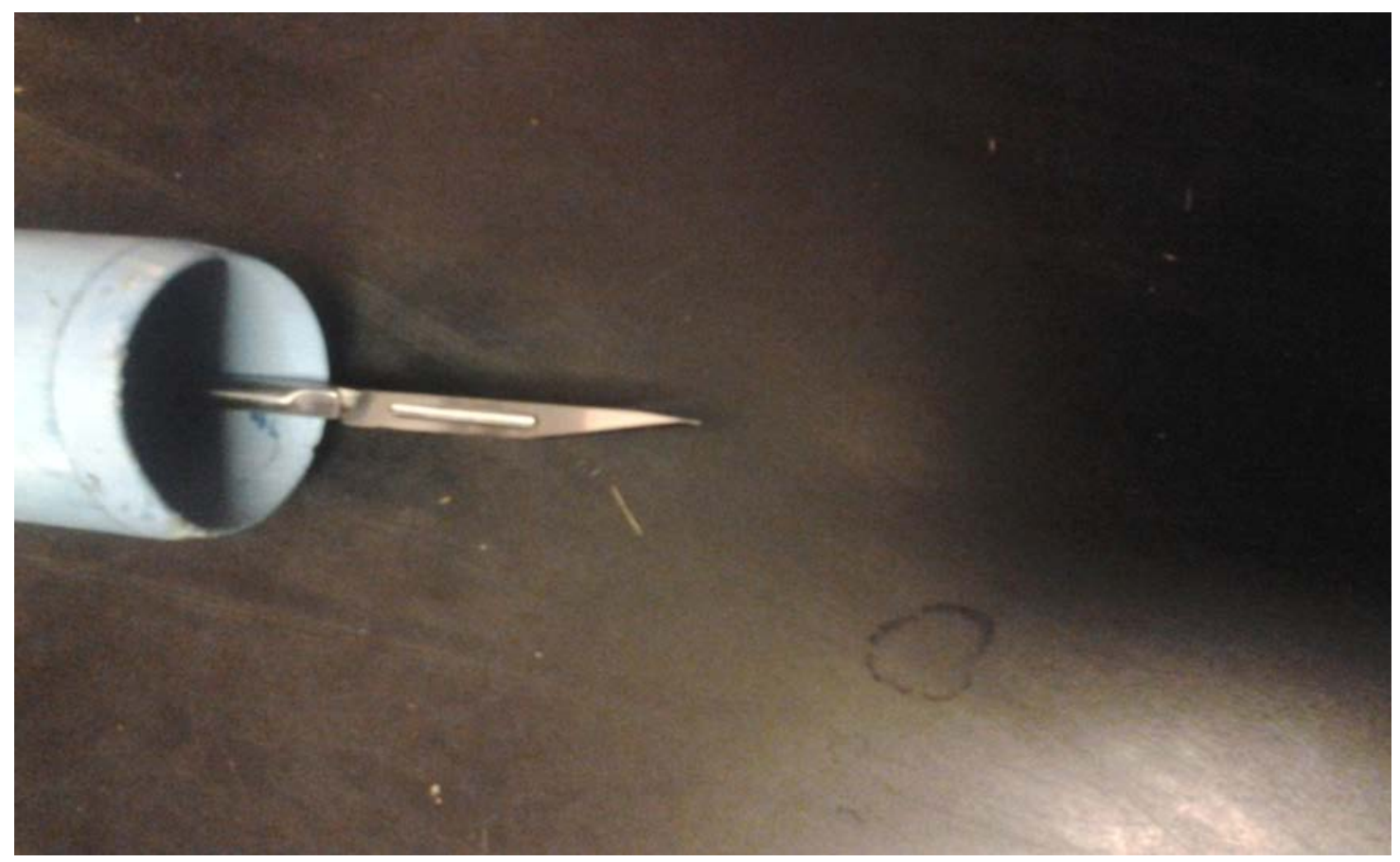

Figure 2. The blade handle passed through the vaginal tube

The blade is pushed to cut the vagina at the 12 o'clock position anteriorly and the 6 o'clock position posteriorly (Figure 3 ). The cut is made wide enough to allow the introduction of the blade of the scissors. Care must be taken to avoid the tip of the blade from injuring any organ. A grasper from the $5 \mathrm{~mm}$ port is used to prevent bladder or bowel injury which can be done by grasping the tip of the blade. Cutting the vagina at the 12 o'clock position is accomplished by pushing the blade handle down towards the floor, so the tip of blade opens at 12 o'clock above the cervix. 


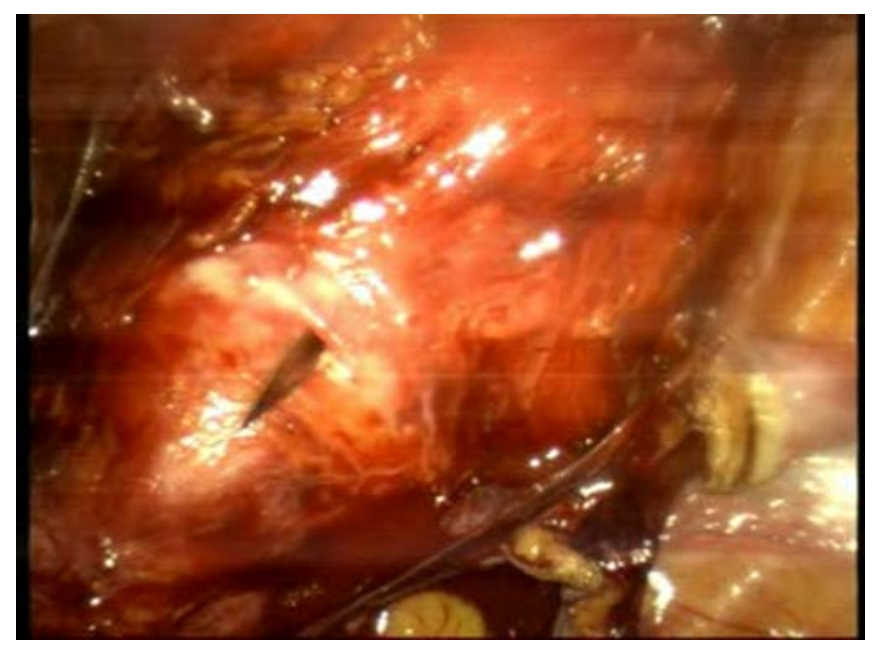

Figure 3. The blade is seen coming from the vaginal tube

If the handle is held at 12 o' clock then the tip of blade will be at 6 o'clock (Figure 4). The surgeon should note that when looked at from below, the perception of direction of blade is reversed since the camera looks from above.

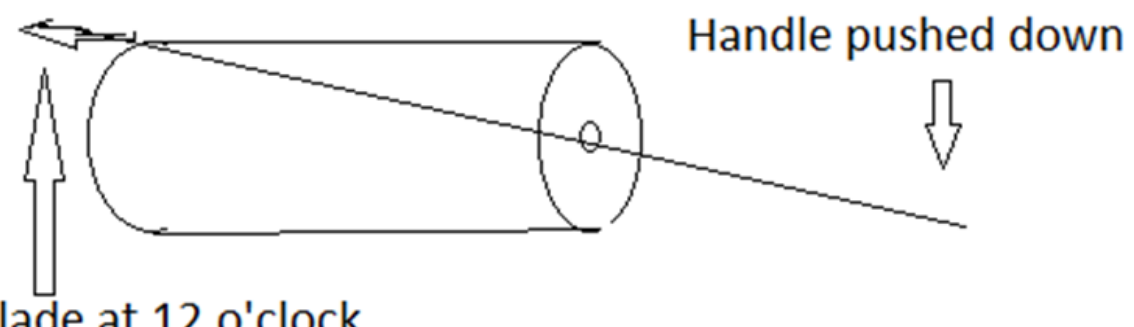

Blade at 12 o'clock

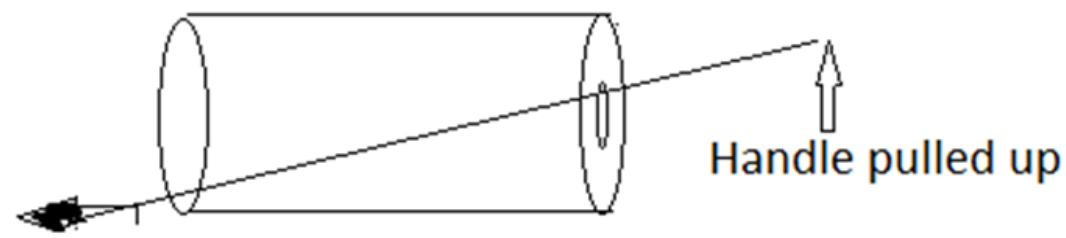

\section{Blade at 6 o'clock}

Figure 4: To demonstrate the direction of the blade and handle.

Blade at 6 o' clock will cut posterior vagina at center.

Blade at 12 o' clock position will cut vagina anteriorly at the center 
The opening is widened with the scissors to cut the vagina from 10 to 2 o'clock anteriorly and from 4 to 8 o'clock posteriorly using the laparoscopic route (Figures 5, $6 \&$ \&). The tube is withdrawn a little to reduce the stretch on the vagina. If a bleeder is seen, it is spot coagulated using a bipolar forceps.

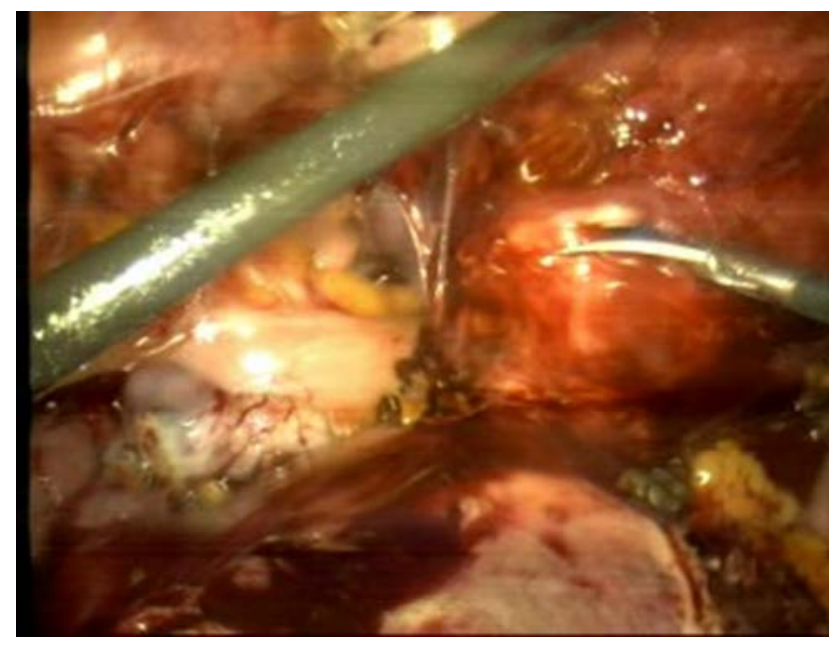

Figure 5. Widening the opening by scissors

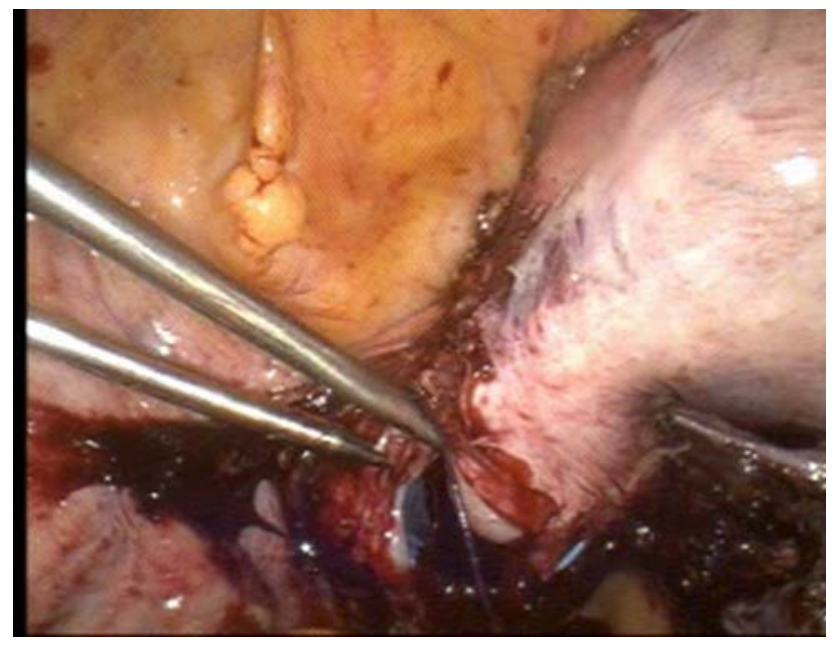

Figure 6. The posterior vagina is opened from the 40 ' clock to the 8 O'clock position

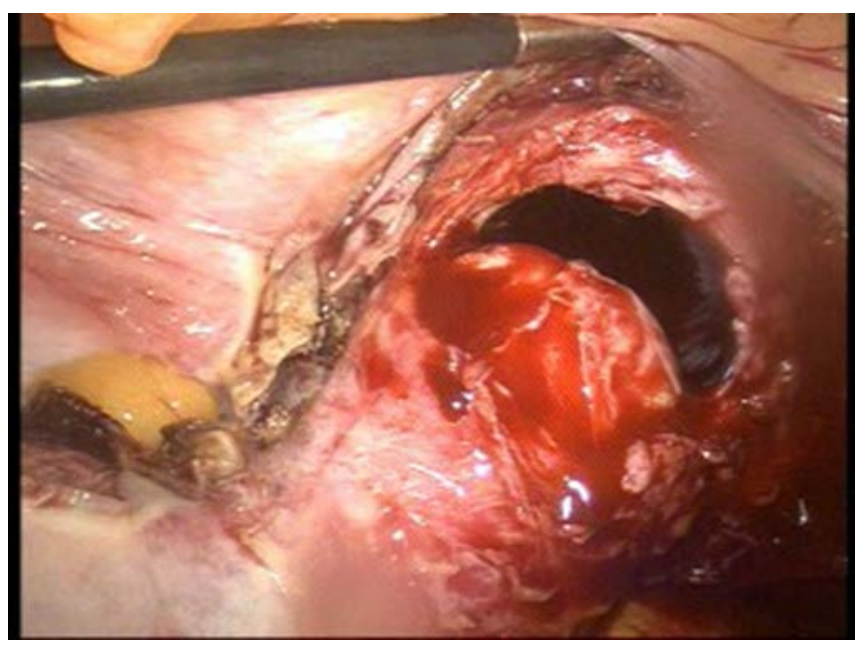

Figure 7. The anterior vagina is opened from the 10 o'clock to the 2 o'clock position. The edge of vagina is seen without coagulation

The lateral attachments of uterus and vagina, i.e. cardinal ligaments, are tied with number one delayed absorbable suture on both sides by extracorporeal knots as this pedicle is thick (Figure 8). The tags are kept long. Then the ligaments are cut along with the vagina.

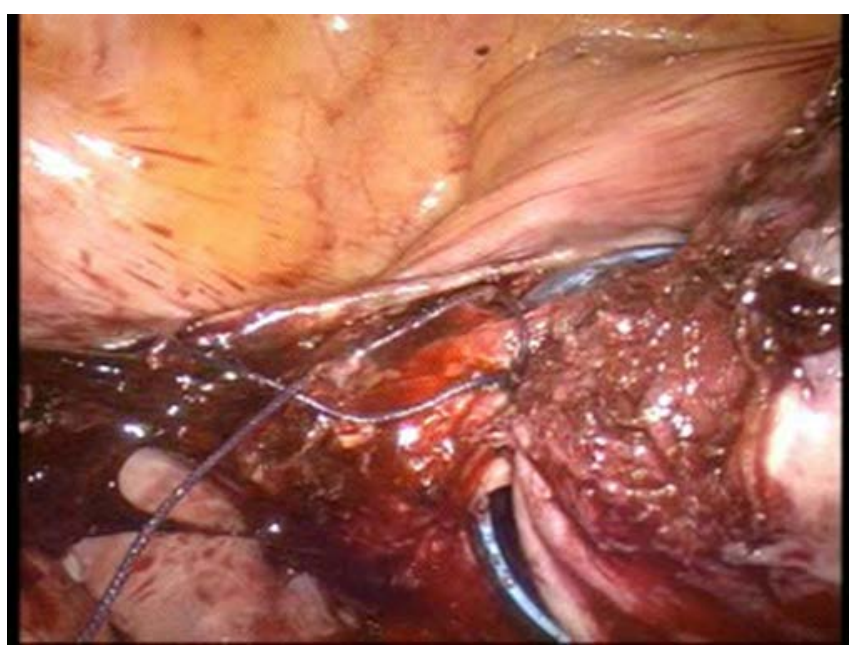

Figure 8. The left cardinal ligament tied with the vaginal angle 
The specimen is removed (Figure 9) and the vagina sutured as usual, either from the vaginal route or from the laparoscopic route. The long tags kept with the cardinal ligaments are tied to the vaginal angle.

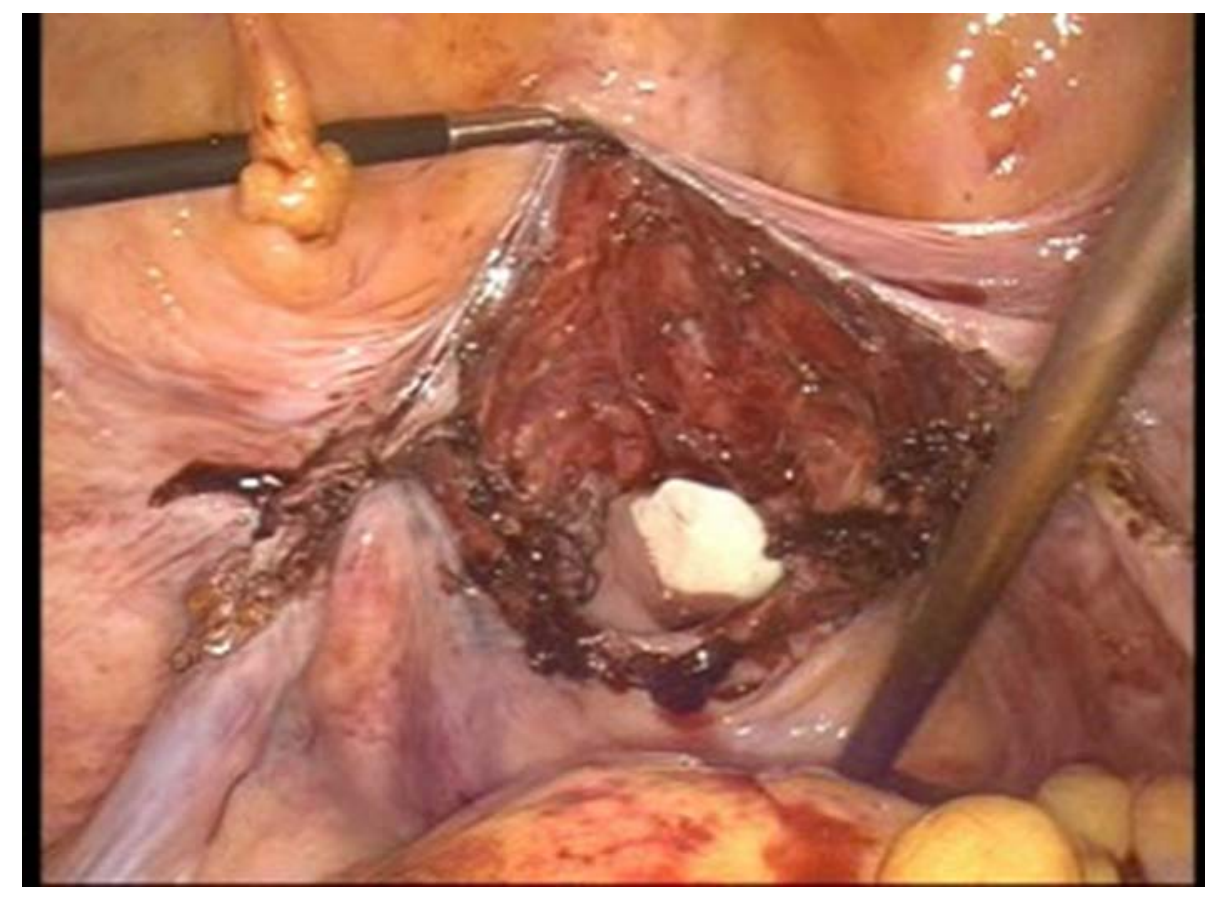

Figure 9. The edge of vagina is uncharred and both cardinal ligaments are tied to vaginal angle with a pack in vagina

\section{Discussion}

A Medline search was done for related literature. The exact cause of vaginal cuff dehiscence is not yet known. The possible causes are impaired wound healing due to thermal damage from energy sources, and vaginal closure techniques such as depth of suture, decreased knot security and infection.

Hur et al. have shown that total laparoscopic hysterectomy has a higher incidence of vaginal cuff dehiscence when compared to abdominal or vaginal hysterectomy. ${ }^{1}$ In a series of 7,286 cases, 10 cases were complicated by vaginal cuff dehiscence. Eight out of these ten cases were a result of total laparoscopic hysterectomy with one each a result of abdominal and vaginal hysterectomy. The relative risk of vaginal cuff dehiscence was significantly higher in total laparoscopic hysterectomy. Their conclusion was that the use of thermal energy in addition to other factors was responsible for the cuff dehiscence. ${ }^{1}$

The main differences in technique between total laparoscopic hysterectomy and abdominal or vaginal 
hysterectomy are the extensive use of an energy source and probably poor suturing techniques.

Uccella et al. have done a multi institutional analysis of 12,398 cases that underwent hysterectomy by various routes. There were 23 cases of vaginal scar dehiscence in total laparoscopic hysterectomy as compared to 9 in abdominal and 6 in vaginal hysterectomy. It was observed that if the vagina is sutured by the vaginal route, the incidence of vaginal scar dehiscence is low. ${ }^{7}$

Fanning et al. studied 463 cases of total laparoscopic hysterectomy and 147 patients who underwent laparoscopic assisted hysterectomy. There were 17 cases in the total laparoscopic hysterectomy group who had scar dehiscence as compared to none in LAVH group. Their conclusion was that the vaginal closure technique was the reason for dehiscence rather than the use of an energy source for colpotomy. Possible vaginal closure technique issues included shallow suture placement, decreased knot security and the suture fraying associated with laparoscopic suturing. ${ }^{8}$

In another study by Kim et al. with 604 hysterectomies, there were 21 cases of scar dehiscence; of these, total laparoscopic hysterectomies were 274, laparoscopic assisted vaginal surgeries were 238 and abdominal radical surgeries were $63 .{ }^{9}$ Out of the 274 total laparoscopic hysterectomies, 169 cases were closed with intracorporeal continuous sutures and 105 cases were sutured by the vaginal route.
Of the 604 hysterectomies, there were 3 eviscerations [0.49\%] and 21 dehiscences [3.47\%]. Dehiscence occurred in 15 of the 274 cases of total laparoscopic hysterectomies. There were 238 laparoscopic assisted hysterectomies and 4 [1.68\%] had scar dehiscence while there were 63 cases abdominal hysterectomies with only two cases [3.17\%] of scar dehiscence. Of the 169 cases of total laparoscopic hysterectomies with intracorporeal continuous suture, four cases of scar dehiscence occurred; whereas, 11 cases of scar dehiscence occurred in the total laparoscopic cases closed with vaginal continuous locking sutures. So the inference was drawn that intracorporeal suturing is better than vaginal suturing in total laparoscopic hysterectomy. ${ }^{9}$

Kumagai et al. studied wound healing in rats that had a midline fascial incision made with either scalpel or electrocautery and then the incision was inoculated with E. coli. ${ }^{10}$ They found that the tensile strength in the wound was significantly less when the incisions were made with electrocautery than with a scalpel. The use of electrocautery was also associated with more frequent bacteremia. This study suggests that scalpel wound healing is better than that of electrocautery. ${ }^{10}$

Klauschie studied the histologic characteristics of the vaginal cuff tissue of patients with vaginal cuff dehiscence. The conclusion drawn was that the cases of vaginal cuff dehiscence had higher levels of acute and chronic inflammatory cells thus delaying the healing. ${ }^{11}$ Vaginal cuff dehiscence has been blamed on poor suturing technique 
rather than excessive energy source. ${ }^{7,}, 8$,

${ }^{9}$ When the vagina is sutured by vaginal route, the incidence is comparable to abdominal or vaginal hysterectomy. In the study by Uccella et al., 12,398 cases were studied; by reducing the power of monopolar current, the rate of vaginal scar dehiscence did not change. ${ }^{7}$

Robinson et al. studied vaginal cuff dehiscence after robotic total hysterectomy, they found that the vaginal cuff dehiscence was the result of thermal spread and cuff tissue damage from electrosurgery used for colpotomy. ${ }^{12}$

Mannivannan et al. studied gingival perfusion pre and post operatively. They compared scalpel wounds with those from electrocautery using Doppler flow studies. They found $30 \%$ more blood flow by the $7^{\text {th }}$ day, $19 \%$ more flow by the $15^{\text {th }}$ day and $11 \%$ more flow by the $30^{\text {th }}$ day in cases where the scalpel was used. As wound healing is influenced by revascularization rate, they concluded that scalpel wound healing may be superior to that of elecrocautery. ${ }^{13}$ Though exact reasons are not known, the following may be some possible causes.

\section{Use of excess energy source}

\section{Poor suturing technique}

In the technique described here, an energy source is not used to cut the vagina, except for the bleeders, that are dealt with by bipolar energy. The sharp edge cuts contribute to better healing as a result of the depth of the suture and more favorable approximation which may reduce the chances of scar dehiscence. With no energy source used, there is no possibility of lateral thermal damage. Although there were no accidental injuries; if an injury were to occur, it could easily be dealt with by suturing because of good visibility. There will be more bleeding with this technique than with the use of diathermy; however, as there are no major blood vessels in this area, this should not be of great concern. This technique is more like the open technique including the fact that the field of vision is good due to no fumes.

\section{Conclusion}

This new approach, due to its advantages of minimal or no use of an energy source for colpotomy and the sharp cut edges of the vagina for better approximation, is expected to reduce the incidence of thermal damage to the lower ureter and urinary bladder and the amount of scar dehiscence. Additionally, the cardinal ligaments are defined, and are tied to the edge of the vaginal angle, as is done in abdominal hysterectomy, to give better support to the vaginal angle. Research needs to be done to collect data using this technique to determine if it does indeed decrease the incidence of vaginal scar dehiscence.

\section{References}

1. Hur HC, Guido RS, Mansuria SM, Hacker MR, Sanfilippo JS, Lee TT. Incidence and patient characteristics of vaginal cuff dehiscence after different modes of hysterectomies. J Minim Invasive Gynecol. 2007 MayJun;14(3):311-7.

http://dx.doi.org/10.1016/i.jmig.2006.11. 005. PubMed PMID: 17478361. 
2. Saidi $M H$, Sadler RK, Vancaillie TG, Akright BD, Farhart SA, White AJ. Diagnosis and management of serious urinary complications after major operative laparoscopy. Obstet Gynecol. $1996 \quad$ Feb;87(2):272-6. http://dx.doi.org/10.1016/00297844(95)00411-4. PubMed PMID: 8559538.

3. Hefermehl LJ, Largo RA, Hermanns T, Poyet C, Sulser T, Eberli D. Lateral temperature spread of monopolar, bipolar and ultrasonic instruments for robot-assisted laparoscopic surgery. BJU Int. 2013 Oct 15. doi:10.1111/bju.12498. [Epub ahead of print] PubMed PMID: 24127773.

4. Gruber DD, Warner WB, Lombardini ED, Zahn CM, Buller JL. Laparoscopic hysterectomy using various energy sources in swine: a histopathologic assessment. Am J Obstet Gynecol. 2011 Nov;205(5):494.e1-6. doi: 10.1016/j.ajog.2011.07.009. Epub 2011 Jul 20. PubMed PMID: 21924395.

5. Sutton PA, Awad S, Perkins AC, Lobo DN. Comparison of lateral thermal spread using monopolar and bipolar diathermy, the Harmonic Scalpel and the Ligasure. $\mathrm{Br} \mathrm{J}$ Surg. 2010 Mar;97(3):428-33. doi: 10.1002/bjs.6901. PubMed PMID: 20101674.

6. Rappaport WD, Hunter GC, Allen R, Lick S, Halldorsson A, Chvapil T, Holcomb M, Chvapil M. Effect of electrocautery on wound healing in midline laparotomy incisions. Am J Surg. $\quad 1990$ Dec;160(6):618-20. http://dx.doi.org/10.1016/S00029610(05)80757-3. PubMed PMID: 2147542.
7. Uccella S, Ceccaroni M, Cromi A, Malzoni M, Berretta R, De laco $P$, Roviglione G, Bogani G, Minelli L, Ghezzi F. Vaginal cuff dehiscence in a series of 12,398 hysterectomies: effect of different types of colpotomy and vaginal closure. Obstet Gynecol. 2012 Sep;120(3):516-23. doi: 10.1097/AOG.0b013e318264f848.

PubMed PMID: 22914459.

8. Fanning $\mathrm{J}$, Kesterson $\mathrm{J}$, Davies $\mathrm{M}$, Green J, Penezic L, Vargas R, Harkins G. Effects of electrosurgery and vaginal closure technique on postoperative vaginal cuff dehiscence. JSLS. 2013 Jul-Sep;17(3):414-7.

doi:10.4293/10860813X1369342251851 5. PubMed PMID: 24018078.

9. Kim MJ, Kim S, Bae HS, Lee JK, Lee NW, Song JY. Evaluation of risk factors of vaginal cuff dehiscence after hysterectomy. Obstet Gynecol Sci. 2014 Mar;57(2):136-43.

doi: 10.5468/ogs.2014.57.2.136. Epub 2014 Mar 15. PubMed PMID: 24678487.

10. Kumagai SG, Rosales RF, Hunter GC, Rappaport WD, Witzke DB, Chvapil TA, Chvapil M, Sutherland JC. Effects of electrocautery on midline laparotomy wound infection. Am J Surg. 1991 Dec;162(6):620-2; discussion 622-3. http://dx.doi.org/10.1016/00029610(91)90122-T.

PubMed PMID:1670238.

11. Klauschie J, Wen $Y$, Chen B, Zhou L, Nunez-Nateras R, Ocal IT, Lam-Himlin D, Kho R. Histologic characteristics of vaginal cuff tissue from patients with vaginal cuff dehiscence. J Minim Invasive Gynecol. 2014 MayJun;21(3):442-6. doi: 10.1016/j.jmig.2013.11.013. Epub 2013 Dec 4. PubMed PMID: 24316139. 
12. Robinson BL, Liao JB, Adams SF, Randall TC. Vaginal cuff dehiscence after robotic total laparoscopic hysterectomy. Obstet Gynecol. 2009 Aug;114(2 Pt 1):369-71. doi: 10.1097/AOG.0b013e3181af68c6.

PubMed PMID: 19622999.
13. Manivannan N, Ahathya RS, Rajaram PC. Scalpel versus electrosurgery: Comparison of gingival perfusion status using ultrasound Doppler flowmetry. J Pharm Bioallied Sci. 2013 Jul;5(Suppl 2):S154-9. doi: 10.4103/09757406.114317. PubMed PMID: 23956596. 